\title{
AUTOCONSERVACIÓN CONTRA NACIÓN. LECTURAS DE LA INTEGRATIONSLEHRE DE RUDOLF SMEND EN LA DOCTRINA JURÍDICO-POLIITICA ESPAÑOLA DE LOS AÑOS TREINTA
}

\author{
Selfpreservation against Nation. Rudolf Smend's \\ Integrationslehre in 1930s Spanish Public Law
}

\author{
SEBASTIÁN MARTÍN \\ Universidad de Sevilla \\ sebasmartin@us.es
}

Cómo citar/Citation

Martín, S. (2018).

Autoconservación contra nación. Lecturas de la Integrationslehre de Rudolf Smend en la doctrina jurídico-política española de los años treinta.

Revista de Estudios Políticos, 182, 99-128.

doi: https://doi.org/10.18042/cepc/rep.182.04

\section{Resumen}

El presente escrito aborda dos cuestiones: el contenido político práctico de la doctrina de la integración de Rudolf Smend y la acogida crítica que esta recibió en la iuspublicística española de la década de 1930, principalmente por parte del constitucionalista Eduardo L. Llorens, autor de una teoría del Estado entendido también como proceso integrador. Aspecto fundamental de la investigación será, por tanto, el contraste entre ambas construcciones teóricas y el hallazgo del principio político activo en cada una de ellas. A tal fin se ha procedido a delimitar el paradigma científico del que las dos participaban y a señalar las diferencias de calado que las separaban. En una revisión crítica de la literatura actual producida en torno a la doctrina de Smend, se lanza una nueva hipótesis de lectura de sus contenidos, útil en este caso para entender las razones del rechazo de que fue objeto por parte de quien ha solido considerarse su seguidor espańol.

\section{Palabras clave}

Derecho constitucional; teoría del Estado; historia constitucional; historia del pensamiento jurídico; República de Weimar; teorías de la integración; nacionalismo. 


\begin{abstract}
This text tackles two issues: the political content of the Rudolf Smend's Integrationslehre and its critical interpretation by 1930s Spanish Public Law, mainly by Eduardo L. Llorens, a Constitutional Law Scholar who developed a State theory based also on the idea of integration. A basic aspect of the research is the comparison between these doctrines about integration and the attempt to find the political principle of each other. With this purpose, the scientific paradigm shared by both theories has been delimited and the disagreements between them highlighted. Through a critical revision of the studies about Smend's Integrationslehre, a new interpretation of its contents has been posed, in order to understand why Eduardo Llorens, usually considered as the main Smend's Spanish supporter, flatly rejected his doctrine.
\end{abstract}

\title{
Keywords
}

Constitutional Law; State Theory; constitutional history; history of legal thought; Weimar Republic; integration doctrines; nationalism. 


\section{SUMARIO}

I. INTRODUCCIÓN. II. PROPÓSITO PRAGMÁTICO DE LA TEORÍA DE LA INTEGRACIÓN. III. UNA CONSTELACIÓN CULTURAL COMÚN. IV. DISCREPANCIA INSALVABLE ENTRE DOCTRINAS. V. LECTURAS CONTEMPORÁNEAS DE LA INTEGRATIONSLEHRE. VI. AUTOCONSERVACIÓN CONTRA NACIÓN. BIBLIOGRAFIA.

\section{INTRODUCCIÓN}

El debate jurídico-político en la Europa de los años 1920 y 1930 tuvo un alcance fundacional. El derecho público español de aquella época se hallaba en trance de europeizarse por completo. No pocos de los juristas que lo integraban y cultivaban estaban perfectamente al tanto de las controversias y los desafíos teóricos de la ciencia constitucional europea (García Fernández, 2016: 17). Este especial influjo de las doctrinas de nuestro entorno en el debate español se tradujo, de hecho, en la importación explícita que algunos de nuestros juristas hicieron de las ideas de maestros franceses, ingleses o alemanes (Martín, 2011: LXVIII-LXX). En la reconstrucción de estas influencias se ha vinculado la doctrina de la integración de Rudolf Smend con la constitucionalización en 1931 del «Estado integral» (Tomás y Valiente, 1997: 2049 ss.). También se han enlazado sus proposiciones teóricas con las de un sólido pero lateral constitucionalista español llamado Eduardo L. Llorens, que colocó asimismo en el centro de toda su sistemática la idea de «integración».

El presente artículo trata de deshacer estos equívocos identificando los contenidos dispares que uno y otro autor atribuyeron a dicho concepto. Del cotejo resultará no solo la evidencia de que Llorens no puede ser considerado discípulo ni continuador de las ideas constitucionales de Smend; se aspira igualmente a identificar el núcleo político de las afirmaciones teóricas del autor alemán, superando con ello la paráfrasis habitual en las interpretaciones convencionales, algo que nos permitirá además desmentir cualquier tipo de ascendencia de la Integrationslehre sobre nuestro primer Estado autonómico. Para ello realizaré en primer lugar un examen sucinto del objetivo práctico de la teoría de Smend. Inscribiré después sus proposiciones y las de Eduardo L. Llorens en una constelación filosófico-política compartida, señalando ulteriormente las diferencias más notorias entre ambas. Realizaré por último un balance de las interpretaciones más o menos actuales de la Integrationslehre para ofrecer finalmente una hipótesis de lectura; con ella podrá captarse mejor 
el propósito político de su doctrina y se terminará de precisar la distancia que la separaba de la de Llorens o de iniciativas constitucionales como la autonomía regional.

\section{PROPÓSITO PRAGMÁTICO DE LA TEORÍA DE LA INTEGRACIÓN}

El concepto de «integración» resultaba de reciente configuración y de creciente circulación en la década de 1930 (Korioth, 1990: 126-9). El propio término y sus múltiples variaciones lingüísticas — «integrar», «integrador», «integral», «integrante»— contaron con numerosas declinaciones de índole jurídico-política. Su formulación alcanzó a textos constitucionales de tono político divergente. Se acaba de recordar que la Constitución republicana calificó en su art. 1..$^{\circ}$ al Estado español de «integral», por ser «compatible con la autonomía de los Municipios y las Regiones». Los autores del proyecto constitucional portugués de 1933 presentaron su obra como «un sistema integral del nuevo Derecho público» (Pérez Serrano, 1932: 233). Y la Carta del Lavoro, en su art. $1 .^{\circ}$, entendió la "Nación italiana» como un «organismo» que «se realiza integralmente en el Estado fascista» (Turati y Bottai, 1929: 35). Como reflejo de esta multifuncionalidad, recurrieron al concepto proyectos partidistas de signo ideológico contrario. En el caso español los términos «integral»o «integrador» sirvieron para describir los horizontes del programa revolucionario socialista o para dar forma al deseo conservador de fundar «un Estado autoritario, integrador y corporativo» (García Santos, 1980: 286, 312, 501-502).

Esta especie de magnetismo del concepto de «integración» operó asimismo en el terreno de las doctrinas jurídicas. Algunas construcciones lo tomaron como referente central de toda su reflexión, y de entre ellas destacó ante todo la elaborada por Rudolf Smend en su Verfassung und Vergassungsrecht porque sistematizó y dotó de contenido filosófico concreto una de las posibles acepciones del vocablo. Lo hizo con relativo éxito, a tenor de la aceptación y desarrollo ulterior que obtuvieron sus sugerencias en la iuspublicística alemana, tanto la propia de entreguerras (Koellreutter, 1929) como la formada ya en tiempos de la República federal (Lepsius, 2008: 267-70), llegando incluso a inspirar la jurisprudencia constitucional (Korioth, 1999: 228 y ss. ${ }^{1}$ ). Dispensándonos de una exposición detallada de la Integrationslehre los numerosos comentarios disponibles sobre ella (Lucas Verdú, 1987: «IV. Conceptos

1 Lepsius atempera esta influencia (2008: 269). Llevan a mi juicio demasiado lejos el influjo de la doctrina de Smend —a la integración europea- Martin Morlok y Alexandra Schindler (2005, 28-30). 
capitales de Rudolf Smend sobre teoría del Estado»; Gozzi, 1988: 291-310; Korioth, 1999: «2.II. Die staatstheoretische Grundlegung der Integrationslehre»; Costa, 2001: 81-87; Unruh, 2004: 132-155; Bisogni, 2005: 47-87; La Torre, 2006: «3. La comunità "integrata”: Rudolf Smend»; Llanque, 2006: 317 y ss.), sí debemos, en cambio, pergeñar sus contenidos fundamentales para poder acometer de modo satisfactorio nuestro estudio comparativo.

La teoría de la integración de Smend respondía a una urgencia de carácter práctico²: la necesidad de combatir la Staatsfremdheit que, procedente de la neutralidad típica del liberalismo, disgregaba las sociedades al extinguir el sentimiento de pertenencia entre sus miembros. Pese a la abstracción de sus planteamientos, el discurso científico se situaba con Smend en un plano eminentemente pragmático, donde los receptores principales eran los dirigentes, magistrados y burócratas y el objetivo perseguido era contribuir a que los ciudadanos se reconociesen en sus instituciones jurídico-públicas. Si el diagnóstico sobre los males que aquejaban a la colectividad señalaba como culpable a la creciente indiferencia política de sus miembros, entonces las teorías normativista y sociológica del Estado se demostraban por completo incapaces de suministrar remedios eficaces contra la crisis.

En efecto, Smend elaboró su teoría de la integración pensando contra el purismo metodológico de Kelsen y contra el positivismo sociológico. El primero, con su obstinado «nihilismo», y coronando la línea del «pensamiento liberal antiestatal», deslavazaba el Estado hasta el paroxismo al cerrar el paso a cualquier tipo de disquisición sobre los «valores materiales» que instituían la comunidad política. El segundo, atrapado en sus categorías epistemológicas binarias y espaciales de "causa/efecto", «sustancia/función", «individuos/relaciones», no lograba superar la representación «estática» y «mecanicista» de la fenomenología sociopolítica y, detenido como estaba en la compilación de hechos empíricos inconexos, le pasaba desapercibida la íntima imbricación vital que los entrelazaba. Y es que, como ya advirtiese Tönnies (1947: 65) —a quien Smend tenía muy presente ${ }^{3}$ - , ese concepto mecanicista de sociedad tenía la consecuencia política de considerar a los hombres «esencialmente separados a pesar de todas las uniones».

En lugar de estas dos vertientes de pensamiento, ambas inhábiles ante la responsabilidad científica de contribuir a la pacificación social, Smend estimaba más provechosas la «literatura política descriptiva» producida en el mundo anglosajón, que abordaba problemas concretos en su aspecto práctico,

2 Para las citas que empleo a continuación, véase R. Smend (1985, 39-127).

3 Las expresas y apreciativas menciones que Smend hace de dicha obra en 1985: 108109. 
y, sobre todo, la «literatura del fascismo», toda ella comprometida con la búsqueda de nuevas fórmulas de consenso y con la articulación de modos eficaces de revigorizar la «vida estatal». Su Integrationslehre se aproximaba al incipiente régimen italiano por vínculos de afinidad, como evidenciaba, a su juicio, la elocuente consonancia terminológica de la definición oficial del "corporativismo fascista» como un modo de organización estatal "integral", es decir, integrador», pero no "“completo"» ni «radical» (Smend, 1985a: 68 n. 67).

Con estas sintonías de partida, y rechazados el formalismo y el sociologismo, Smend se proponía recolocar la fundamentación teórica del Estado en el campo de la «ética política» para, desde ahí, elaborar una "teoría material» que, trascendiendo toda forma de relativismo disolvente, abarcase «el ámbito cultural y espiritual de la dinámica estatal». Pese a su explícita preferencia por la bibliografía que, con su pragmatismo, resultaba funcional al arte de gobierno, Smend optó por recurrir a una metodología alambicada que revestía de cientificidad sus propósitos de intervención práctica. Así, para evitar la disecación del Estado, Smend se adscribió a la geisteswissenschaftliche Richtung, la cual, constituida conceptualmente por las categorías acuñadas por Hegel, Dilthey, Husserl y Litt (Rennert, 1987: 67-96)4, trataba de aprehender la sociedad política en su totalidad, concibiéndola como un proceso cultural caracterizado por la síntesis continua de todas las polaridades. Smend combinó de esta forma fenomenología y dialéctica para concluir obteniendo una visión de la colectividad política como "estructura unitaria» constantemente reproducida, aun de forma inconsciente, por la experiencia particular de sus componentes individuales.

En contraste con el modelo racionalista que entendía la sociedad como unión de sujetos asociados para satisfacer finalidades comunes, Smend secundó una representación teórica que englobaba el aspecto sentimental de la existencia colectiva, acentuaba la ligazón «existencial» entre el individuo y la comunidad y caracterizaba la convivencia como «un proceso de actualización funcional y de reproducción» de la "unidad de sentido» espiritual que subyace a toda agrupación humana. El fenómeno de la «integración» consistía precisamente en eso: en la materialización, despliegue y renovación incesantes de dicha unidad profunda.

De este modo, el principio capital de la Integrationslehre, más que en el proceso mismo de la integración, radicaba en la infraestructura cultural que las acciones sociales actualizaban continuamente, o, por expresarlo con léxico sociológico de época, en "la unidad del ser orgánico» que prestaba «fundamento», dotaba de coherencia y yacía «por debajo» de la pluralidad empírica,

4 Hanns Mayer destacaba la ascendencia hegeliana (Mayer, 1931: 36-37). 
exterior y aparente que se manifestaba ante los ojos del observador (Tönnies, 1947: 225). Tanto el carisma de los dirigentes públicos como la Herrschaft inherente a toda organización colectiva, los procedimientos instituidos para adoptar decisiones colectivas así como la simbología y las liturgias patrióticas, todos estos elementos, aunque ejerciesen de diferente forma su función integradora, se hallaban referidos por igual al conjunto de valores materiales que conformaba la identidad cultural del pueblo, a los cuales desarrollaban y vivificaban constantemente.

Aparte de por esta permanente remisión a la armazón orgánica de la colectividad, la ontología política de Smend se caracterizaba por la práctica indistinción entre la dinámica social y la vida del Estado, pues ambas consistían en procesos de síntesis que desplegaban dicha matriz axiológica unitaria y precedente. La pertenencia sustancial del individuo a su comunidad y la renovación permanente del todo social a través de la experiencia de sus partes integrantes se transfiguraban así en la inserción integral del ciudadano en el ámbito estatal y en la realización continua de los valores comunitarios mediante las decisiones particulares de los órganos del Estado. Pero si la reflexión de Smend aparece siempre atravesada por la disyuntiva entre, de una parte, el carácter material de la esencia cultural de la sociedad, y de otra, su progresivo desvanecimiento en la conciencia política de los individuos, entonces su teoría se escinde, por un lado, en una descripción de la existencia dinámica de los valores constitutivos de la colectividad, de su afloramiento y concreción infinitos en las relaciones sociales efectivas, y por otro, en un llamamiento a los cuadros dirigentes para que, con sus decisiones, actualizasen y propagasen dichos valores, fomentando su realización por parte de las masas y creando en ellas «un sentido colectivo» del que supuestamente empezaban a carecer $^{5}$.

Su doctrina se inscribía en la corriente «transpersonalista», que insistía en la divisa según la cual el Estado solo puede existir «a partir del individuo y en el propio individuo». En sus formulaciones, el carácter primordial de la esencia orgánica de la comunidad fundamentaba limitaba y legitimaba el ejercicio del poder al tiempo que le asignaba sus fines éticos propios. Pues bien, a pesar de estos dos factores, si damos por esencialmente sesgado para los tiempos pluralistas de entreguerras cualquier tipo de Wertgemeinschaft, de comunidad de valores materiales unitarios, el valor sociológico práctico de la doctrina de Smend consistía en un llamamiento a determinadas minorías políticas para que, apoderándose de los órganos estatales e instrumentalizándolos en sentido

Andreas Anter anota también esta ambivalencia e inscribe su aportación en «los discursos sobre la decadencia del orden» (Anter, 2009: 43). 
cultural, lograsen que las masas socializasen de acuerdo a su concreta y muy particular representación del todo social.

A día de hoy, se puede estar más o menos conforme con esta descodificación sociológica de la Integrationslehre. Sin embargo, en nada desmentiría su posible impugnación el hecho de que así fuese interpretada por quien se entiende que la importó desde Alemania al debate jurídico-político español.

\section{UNA CONSTELACIÓN CULTURAL COMÚN}

El uso reiterado que en la teoría del Estado del constitucionalista Eduardo L. Llorens obtuvo el término «integración» ha conducido a los estudiosos a relacionar sus concepciones con la conocida doctrina de Rudolf Smend. Esta significativa homonimia ha provocado así el ostensible error de estimar a Llorens su "más destacado seguidor español, sino el único en su momento" (Molina Cano, 2005: 476). Cuando la observación ha penetrado un poco más en las concepciones de los respectivos autores se ha percatado inmediatamente del diferente sentido que ambos atribuyeron al vocablo «integración»: si, de un lado, Smend lo conjugó en aplicación del «método de las ciencias del espíritu», Llorens, por su parte, se inspiró en la tradición sociológica (Lucas Verdú, 1987: $150-152)^{6}$.

Cuando Llorens ha sido objeto de atención monográfica se ha abundado en esta dispar procedencia, asociándose el nombre de Llorens al de Franz Oppenheimer (Guillén Kalle y Almoguera Carreres, 2006: 29-35). Ambos autores atribuyeron no obstante un significado bien diverso al concepto. La politische Integration que Oppenheimer postuló consistía en la "dominación» de los elementos sociales más poderosos sobre los más débiles, algo explícitamente repudiado por Llorens como principio de organización social (1934b: 23). Y es que el lugar primordial que en la teoría social de Oppenheimer ocupaba la Interessenkampfe der Klassen y la consiguiente división entre «una clase dominante» y otra "dominada» (1990: 124-138) eran puntos por completo ajenos a las convicciones del constitucionalista de Reus, quien negaba categóricamente entidad científica al antagonismo estructural entre los intereses.

Con estos antecedentes no llega a deshacerse del todo la confusión de considerar que la obra de Llorens constituyó una suerte de citación española de las sugerencias teóricas de Smend. Para distinguir con rigor las proposiciones de ambos autores conviene que nos detengamos en la interpretación

6 El equívoco que relaciona a Llorens con Smend proviene, sin embargo, del propio Lucas (1976: 157 n. 263). 
crítica que el constitucionalista catalán realizó de la conocida Integrationslehre. Pero antes de pormenorizar en los motivos diferenciales, debemos reparar en que, por encima de las divergencias, ambas versiones de la idea de integración expresaban un universo intelectual compartido.

Las dos conjugaciones del principio integrador se inscribieron en una misma línea teórica, secundada también por autores como Georges Gurvitch y Dietrich Schindler ${ }^{7}$, que, de un lado, tenía el propósito de recordar la condición total que por encima de las fracturas particulares definía la sociedad, y de otro, aspiraba a superar, mediante un ejercicio de síntesis dialéctica, la división entre el normativismo y el empirismo sociológico que escindía la teoría jurídica del momento, pues ambos métodos de conocimiento estaban siempre condenados a comprender un solo aspecto de la completa realidad sociopolítica, con reprobable descuido de los restantes y - sobre todo- del conjunto.

Tanto la propuesta de Llorens como la de Smend se alojaban así en un paradigma filosófico común, cuya seña distintiva más sobresaliente era la postulación del carácter total, previo y absoluto de la estructura social, y la posterior atribución a esa totalidad de una "eticidad» material irreductible tanto a las normas formales que la canalizaban como a las manifestaciones empíricas en que se expresaba. Esta "metafísica de los "fondos" o "trascendentales objetivos" (Medina Echavarría, 1935: 118 y ss.), afín a la exploración fenomenológica de las esencias de Husserl, a la ética de Scheler y a la ontología neoidealista, y opuesta al criticismo kantiano que predicaba la realidad cognoscible de «la subjetividad trascendental», "totalizaba» su objeto de análisis e insistía siempre en "la coherencia a priori de las multiplicidades empíricas» (Foucault, 1997: 240-244). Pero al sustraer el objeto a las reglas subjetivas del conocimiento, la esencia de la sociedad que aducían estas «filosofías de lo absoluto» se tornaba nebulosa y enigmática, aprensible solo a través de expedientes que excedían el análisis meramente racional como la intuición, y cuyo significado sociológico no era sino la ratificación teórica "de las relaciones existentes», lo cual explicaba su conservadurismo político y su inevitable tendencia a entonar siempre el "permanente "regreso a"» (las esencias) (Adorno, 2005: 68).

La matriz de las reflexiones de Smend y Llorens consistía, pues, en una noción hipostasiada de la unidad social, en función de la cual operaban todas las estrategias cognitivas desplegadas, incluido el método dialéctico. Era también propio de este modo de pensar la insistente conciliación —enunciada

7 No es casual que Dietrich Schindler, recorriendo teorías afines al método dialéctico que él aplicaba, se ocupase en tono celebratorio de la conocida monografía de Smend (Schindler, 1931: 251-252). 
contra el positivismo descreído y el formalismo relativista — de la realidad y el valor, si bien tras dicha conciliación, aparentemente ponderada, siempre aparecía una sensible inclinación a realzar el aspecto ético-material de la unidad, considerado como una realidad objetiva superpuesta al pluralismo axiológico realmente existente en sociedad. Así pues, tanto en Smend como en Llorens la integración significaba el proceso a tenor del cual esa unidad objetiva, total, inmanente y de naturaleza moral que distinguía a cualquier colectividad humana de rango político se desarrollaba y superponía permanentemente a todas las diferencias, consideradas siempre como transitorias y accidentales.

Además de esta significativa confluencia, sus diferentes aplicaciones del término integración coincidían en su extensión semántica y en su estructura comunicativa. El concepto penetró en la teoría política con el propósito de dotar de dinamismo a la representación de la sociedad, anclada hasta el momento en categorías "fisicistas», que si bien podían resultar adecuadas para describir la situación cultural del estático mundo político decimonónico se mostraban incapaces de hacer inteligibles los momentos céleres y convulsos en los que la historicidad de los principios y las instituciones se hacía drásticamente presente, como fueron los años veinte y treinta del pasado siglo.

De entre todas las deficiencias del modelo anterior que esta cinética social pretendía abolir, destacaban ante todo la concepción de los individuos como entidades esencialmente diferenciadas y separadas y la comprensión de la realidad política a través de la dicotomía «Estado/sociedad». En su lugar, pretendía colocar una visión de la sociedad en la que sus miembros estuviesen mutua y sustancialmente compenetrados, y una representación de la realidad política como imbricado entretejimiento de las esferas social y estatal, como una conjunción inextricable de ambos polos que permitía sostener tanto la integración de los individuos en las instituciones estatales como la necesaria adherencia de las decisiones del Estado al relieve efectivo de la sociedad.

Contrario a la comprensión de la sociedad como escenario de oposiciones irreductibles, el concepto de «integración» se acunó y difundió justo cuando su corroboración empírica se hacía poco menos que imposible, lo cual significa, por una parte, que su sentido era estructuralmente normativo, pues su proposición resulta inconcebible en sociedades perfecta y espontáneamente integradas, y por otra, que su enunciación traslucía justamente aquello que negaba: el conflicto, la discordia, la división. A este respecto, podría entonces concluirse que la integración suponía una suerte de compensación teórica de la división social imperante, que al acentuar la unidad con tanta intensidad como esta faltaba en las relaciones efectivas mostraba la terrible impotencia del pensamiento frente a unos acontecimientos que lo desbordaban.

De la supremacía de su aspecto prescriptivo se infiere el tercero de sus atributos comunes, que relaciona en unos términos harto peculiares el 
mensaje de la ciencia jurídica con su receptor más prominente: el titular del dominio político. En este sentido, antes de que la ciencia terminase agotándose en una función meramente ancilar del poder, lo cual acaecería durante los totalitarismos, y a diferencia del discurso decimonónico, que aconsejaba al arte de gobierno en el mismo terreno conceptual en que este se desenvolvía, el término «integración» era ahora síntoma de una nomenclatura científica diferenciada pero referida igualmente a los centros de decisión política. En última instancia, su significado consistía, más que en la simple orientación ideológica, en la fijación de objetivos político-constitucionales precisos y en el establecimiento de estándares pragmáticos de valoración de la actividad política, enjuiciada siempre de acuerdo a su capacidad para impulsar y consolidar el proceso de «integración ${ }^{8} »$.

Así pues, tanto en la Integrationslehre de Smend como en las ideas planteadas por Llorens podemos observar cierto isomorfismo filosófico y conceptual y un destinatario común. Tal homogeneidad de partida explica que, salvando las diferencias, Llorens adoptase en ocasiones un léxico de clara remembranza smendiana, como cuando, al referirse a la actividad de los Gobiernos y Parlamentos, afirmaba que «integra[ban] funcionalmente el Estado en su unidad política» (1934b: 31). Sin embargo, la discrepancia entre ellos era tan profunda que incluso cuando Llorens se aproximaba a la terminología utilizada por Smend lo hacía para criticar su postura desde el interior de sus mismas concepciones.

\section{DISCREPANCIA INSALVABLE ENTRE DOCTRINAS}

La diferencia fundamental entre ambas doctrinas de la integración debe ubicarse a mi juicio en la disímil concepción que estos dos autores tenían de la estructura originaria de la totalidad social que los individuos y los poderes públicos debían reproducir y actualizar. Por otro lado, participando ambos de la misma cosmovisión dialéctica y "transpersonalista", Llorens censuraba a Smend recaer en aquello contra lo cual se revolvía esta novedosa corriente intelectual, a saber: la visión «unidimensional» de los hechos sociopolíticos y la concepción «suprapersonal» del Estado. Abordemos ambas cuestiones.

Con unas construcciones excesivamente alambicadas, la idea de integración sostenida por Smend tenía para Llorens el mérito de haber resaltado un

8 «La integración como pauta poco menos que suprema de valoración moral», eso es lo que Smend proponía en su teoría en opinión de Juan Antonio García Amado (1997: XXI). 
«elemento importante» de la dinámica social, como era la capacidad integradora de la "idiosincrasia de los individuos", de las "personalidades prominentes» $\mathrm{y}$ de los «símbolos en torno a los cuales se agrupa un pueblo» (1932: 114). Mas con dicho planteamiento no podían abarcarse todos los pormenores del complejo proceso social. Y tampoco los que Smend destacaba eran de una relevancia integradora tan sobresaliente, pues los miembros de la colectividad no solían coincidir en sus cosmovisiones político-culturales, manteniendo por lo común convicciones «distintas» e incluso "contrapuestas» (1934a: 57), ni «los grandes estadistas» eran tan frecuentes como para «basar una integración en su constante presencia» (1932: 114) ${ }^{9}$.

En opinión de Llorens podía ocurrir justo lo contrario: que, debido a su genuino carácter irracional, fuesen precisamente los aspectos que Smend destacaba de la evolución social los que contenían mayor potencial disgregador. Así ocurría al menos con el factor carismático y con la simbolización de los valores constitutivos de la comunidad, los cuales, extrapolados del terreno estrictamente «sentimental», podían servir de base al despotismo, ya que al considerar a determinados individuos como la personificación de «la unidad del pueblo» amparaban el predominio de ellos sobre el resto de la colectividad (1934b: 31).

Llorens pensaba que con la doctrina de Smend la esfera estatal se apoyaba en categorías románticas racionalmente inaprensibles, las cuales, al no ser susceptibles ni de fiscalización pública ni de individualización de la responsabilidad, resultaban políticamente "peligrosas». Para evitar consecuencias indeseables, la solución científica más equilibrada estribaría en conceder trascendencia al elemento afectivo rescatado por Smend, pero a condición de reputarlo como un momento más del completo proceso integrador, y de subordinarlo a la racionalmente discernible «consciencia de la solidaridad» entre los intereses (1934b: 33). Y es que debe tenerse presente que mientras la famosa obra de Smend se encontraba empapada de giros vitalistas e irracionalistas, las disquisiciones de Llorens, fiel continuador del liberalismo decimonónico, resultaban mucho más sobrias y convencionales, como advera el hecho de su continua mención a la conciencia racional como único instrumento con que aprehender la profunda estructura unificada del movimiento social con desprecio de expedientes cognitivos como la «intuición» (1933a: 200), celebrados, sin embargo, por las corrientes fenomenológicas.

La contestación de Smend a este tipo de consideraciones se enmarcaba igualmente en la interpretación divergente que ambos autores hacían del

9 Resonaba aquí el sensato escepticismo de Max Weber: «Al fin y al cabo, sólo con suerte aparece cada cien años un genio» (Weber, 1991: 116). 
paradigma que decían secundar. Contemplado desde su punto de vista, aunque Llorens se esforzase por desembarazarse del lastre mecanicista del positivismo sociológico, su concepción del Estado como «medio para la consecución de fines individuales y sociales» (1932: 13) le hacía incurrir de lleno en el acostumbrado vicio liberal de «racionalizar toda la vitalidad de la integración» y de «transformarla en un mecanismo teleológico» que perseguía el cumplimiento de "valores abstractos superiores ${ }^{10}$ ». Al apoyar siempre sus reflexiones en la contraposición entre lo «mecánico» y lo «orgánico», la fundamentación de la sociedad y del Estado en la armonía entre los intereses que Llorens secundaba no podía representar para la perspectiva ensayada por Smend sino una evidente manifestación del mecanicismo que desustanciaba la existencia política, puesto que, en lugar de colocar el principio del orden en la esencia imperecedera que regía el desenvolvimiento social, lo ubicaba en una instancia "post rem y extra res», en un acontecimiento «siempre en formación», nunca concluido y, por tanto, con un valor aglutinante «nominal, ideal, ficticio ${ }^{11}$ ».

En resumen, la clave de la controversia en este punto se cifraba entonces en concebir la acción humana como una actualización de la unidad orgánica, sustancial y precedente que dotaba de sentido la convivencia colectiva (esto es, como «voluntad esencial», por expresarlo en los referidos términos de Ferdinand Tönnies), o bien en entenderla como realización de principios ideales, como persecución de fines exteriores al hombre y, por tal motivo, alienantes y constitutivos de unidades frágiles y artificiales (a lo que este mismo autor designaba como "voluntad arbitraria»). Si la Integrationslehre de Smend se decantaba en el primer sentido sustancialista, la doctrina de la integración de Llorens lo haría en el segundo, de orientación instrumental y utilitarista.

Desde la posición adoptada por el catedrático de la Universidad de Murcia, la retórica vitalista característica de Smend no lograba dilucidar la naturaleza del Estado porque, empeñada en referirla a unos «valores materiales» de controvertido estatuto, se alejaba del fundamento racional que justificaba su existencia: la salvaguarda de los «intereses primarios comunes» de la "colectividad política» (Llorens, 1933a: 137). Solo atendiendo al contenido de las decisiones institucionales, y a su ajuste a las necesidades sociales reales, podía aislarse un objeto de análisis para el derecho constitucional científicamente cognoscible a la vez que se conseguía fijar un criterio sólido para, por un lado, valorar la acción de gobierno y, por otro, explicar la adhesión de los miembros de una colectividad a

10 Como serían el «interés común» o el «interés general» con frecuencia invocados por Llorens (Smend, 1985a: 83 y 101).

11 Vuelven a ser palabras extraídas de la crítica que al concepto de Gesellschaft hiciese Tönnies (1947: 79 y 225). 
las directrices emanadas de sus órganos políticos, causada no tanto por identificaciones románticas como por el convencimiento utilitario de que las normas satisfacían sus propias necesidades (Llorens, 1934b: 49). La integración no podía consistir entonces en la permanente actualización de una volátil sustancia colectiva, sino en la progresiva concordia entre las voluntades determinada por la objetiva, material y necesaria interdependencia que las vinculaba. A juicio de Llorens, el error de Smend radicaba en creer que, debido a su carácter económico, esta solidaridad que anudaba los intereses carecía de médula espiritual, cuando sucedía justamente lo opuesto, pues era precisamente ella la que proporcionaba la medida racional de la justicia.

Pero si a Llorens le parecía censurable la Integrationslehre era, ante todo, porque creía que, en el fondo, propugnaba una intensificación del momento de la decisión política. Desvinculada la fase decisoria de los supuestos materiales de su formación, situada de lleno en el terreno movedizo de las sustancias espirituales colectivas, el resultado práctico que irremediablemente se obtenía era una integración producida exclusivamente como consecuencia del sometimiento a los mandatos del Estado. Observadas desde el ángulo de la política, y dada la esperable interpretación abusiva que los titulares del poder público harían de los valores comunitarios en que se fundamentaría su ejercicio, las conclusiones que Smend proclamaba se distinguían no solo por ser contrarias a toda doctrina liberal, sino, sobre todo, por desembocar directamente en una apología de la dictadura, como demostraba para Llorens el hecho de que en su célebre obra se infiriese frecuentemente "la totalidad de la integración» de las medidas adoptadas por un Estado como el «fascista» (1933a: 140).

Llorens no fue el primero ni el único en señalar esa íntima relación entre la Integrationslehre y el autoritarismo político. Nicolás Pérez Serrano (1932: 233), por ejemplo, consideraba el vocablo «integral» «muy propenso a encubrir tendencias antiliberales, como las que anidan bajo la teoría integralista de Smend», y añadiría pocos años después que «difícilmente p[odía] concebirse expresión más vigorosa de una integración personal» que el Führerprinzip (1984: 568). Con terminología muy parecida a la desplegada por Llorens, Georges Gurvitch sostenía que «para Smend el derecho de integración no se distingu[ía] en absoluto del derecho de subordinación» (1932: 11 n. 2), esto es, de una forma de organizar la sociedad adecuándola a los mandatos heterónomos del Estado. El propio Kelsen terminaba su alegato contra la teoría de la integración advirtiendo de que tal «doctrina de la "realidad" del Estado s[ervía] a fin de cuentas — se quiera o no- a la lucha contra la Constitución de la República alemana» (1997: 147). Hanns Mayer señalaba cómo Smend se separaba de las construcciones de Litt al entender en términos objetivos el Wertzusammenhang, y no como construcción subjetiva dependiente de los 
participantes en una relación social ${ }^{12}$. Ya en tiempos totalitarios, y en contraste con estas apreciaciones, pero confirmando en cierto modo su sentido, Francisco Javier Conde (1942: 157 y 170) sostendría que Smend se encontraba «a punto de traspasar la línea» del pensamiento «demoliberal», y si no lo hacía era sencillamente porque no apelaba a la "comunidad de valores» como algo realmente existente, sino como una entidad necesitada de su consolidación por el Estado.

La Integrationslehre permitía en cualquier caso lecturas divergentes. Hubo quien la entendió como una atadura improcedente a la capacidad estatal de decisión. Cabía así interpretarla como una "pedantería» que confundía el imperativo estatal con la trama de las relaciones sociales, sometiendo indebidamente el «seńorío» del Estado a valores objetivos precedentes (Gómez de la Serna, 1950: 19 y 31). No era esta la posición que ocupaba Llorens ni los autores antevistos. Para ellos, la remisión a ese presunto código axiológico definitorio de una comunidad comportaba no una mutilación, sino la ampliación del margen decisorio de la autoridad política ${ }^{13}$.

La contestación de Llorens a la oculta propensión autoritaria de la Integrationslehre se detuvo además en la distinción que Smend marcó entre el derecho político y el administrativo. Si para el constitucionalista de Reus ambos se encontraban vinculados por igual al mandato superior de realización de la justicia a través de la armonización de los intereses, para Smend el derecho administrativo era una magnitud puramente "técnica», opuesta al Staatsrecht, que ya sí tenía «lo político», entendido en términos decisionistas, como «objeto». El derecho político tendría así como su asunto propio la «totalidad de las instituciones y de las funciones» a través de las cuales el Estado se integra a sí mismo en nuevas formas de «unidad», mientras al administrativo cumpliría la «reglamentación» de dichas instituciones y funciones de modo que se realizase la "voluntad del Estado así constituida» (Smend, 1994b: 82). Contrario al dogma de la personalidad soberana del Estado, Llorens (1933a: 173) interpretaba esta propuesta de distinción como una colocación de la actividad administrativa fuera de la órbita del derecho, esto es, de la consecución de la justicia a través de la coordinación de los intereses. Y con ello, a su juicio, se «tendía a fundamentar científicamente la prepotencia de una dictadura».

12 Smend incurriría así en una «identificación de las conexiones de sentido y de las conexiones de valor» ajena a las sugerencias de Litt y la fenomenología (Mayer, 1931: 43-44).

13 Por eso llama la atención que hoy se aduzca la «escasa incidencia que el concepto de decisión» tuvo en su doctrina (Bisogni, 2005: 80). Más correctamente, José A. Estévez Araujo (1988: 114), o Angelo Abignente (1992: 220), quien señala la secreta «centralidad de la soberanía y del poder» en la doctrina de Smend. 
Cayendo fuera del terreno científico «el prejuicio» que «sugestiona[ba] su doctrina ${ }^{14}$ ", lo que Llorens insistía en censurar a Smend era que, al basar la "organización estatal» en la "voluntad de dominación ${ }^{15}$ », subvirtiese los postulados metodológicos de los que decía partir, traicionase la inspiración teórica de «su maestro" Litt y terminase ofreciendo una visión unidimensional y suprapersonal de la realidad sociopolítica, en la que sus componentes aparecían superpuestos, jerarquizados y escindidos entre sí.

Efectivamente, tal y como "ha[bía] mostrado Kelsen», un "contraste entre sus supuestos y sus resultados» recorría toda la reflexión de Smend. En ella, los extremos del «derecho» y la «integración» eran incomprensiblemente segregados, en el erróneo entendido de que el primero había de someterse a los dictados de la segunda, cuando en realidad eran polos inextricables, dado que el derecho contribuía al proceso integrador del mismo modo que lo presuponía. Además, al permitir que los mandatos estatales se autoproclamasen intérpretes únicos de los valores comunitarios, Smend basaba la dinámica social en "uno sólo de sus aspectos», la subordinación, que era precisamente "el más primitivo, mecánico y de precaria estabilidad», es decir, el menos integrador de todos. Por último, en lugar de comprender el Estado como un equilibrio móvil entre tendencias equivalentes de opuesta polaridad, como una unidad compleja formada de elementos en tensión, en la que «la existencia de cada uno de ellos e[ra] imposible si no se da[ban] todos simultáneamente», Smend lo representaba disgregando la sustancia cultural de la comunidad, los miembros de esta y los órganos estatales para, finalmente, establecer una discutible "preeminencia del Estado sobre el individuo» en nombre de la colectividad (Llorens, 1933a: 140 y 183-184).

Llorens se alineaba así con Kelsen a la hora de lanzar objeciones contra Smend, pero sin secundar por ello sus premisas metodológicas. En principio, las coincidencias entre ambos autores a este respecto son abundantes. Tanto Kelsen como Llorens afeaban a la doctrina de la integración el alterar el sentido originario de la fenomenología de Litt. Les resultaba asimismo una teoría rebuscada y conceptualmente oscura — como todas las plagadas de metafórica vitalista-, además de cargada de intencionalidad política, dato que comprometía su rigor científico. Por último, ambos situaban a

14 Esto es, la idea de esos valores objetivos unitarios que proporcionaban el esqueleto de una comunidad y que le llevaban a someter al individuo al Estado (Llorens, 1933a: 183).

15 «En cualquier tipo de organización estatal toda la vida política tiene en definitiva como finalidad la configuración y manifestación de una voluntad de dominación» (Smend, 1985a: 91). 
Smend en la tradición organicista y lo acusaban de mantener una noción «suprapersonal» del Estado muy útil al «método de dominación» practicado por el fascismo. Sin embargo, la polémica entre Kelsen y Smend se inscribía en un duelo de perspectivas epistemológicas ajeno en cierto modo a los postulados conceptuales de Llorens ${ }^{16}$.

Aparte de revelar la falla que separa los «paradigmas constitucionales» austriaco y alemán (Jakab, 2010: 134), esta famosa controversia es una muestra, entre tantas otras, del desencuentro entre modelos científicos inconmensurables entre sí característico de las épocas revolucionarias en la historia de las ciencias (Kuhn, 1987). En este caso particular, la discrepancia se debía a las irreconciliables dicotomías de partida empleadas por ambos autores: realidad y valor, en Smend, causalidad y normatividad, en Kelsen. Mientras que Smend entendía la realidad jurídica cargada de valores morales, Kelsen excluía de la validez del derecho toda referencia cultural a los valores, por entenderla como una recaída en la esfera biológica y psicofísica de la causalidad o como una reprochable infiltración de hábitos iusnaturalistas en la reflexión jurídica objetiva. En este punto, Llorens se desenvolvía por entero en el plano antipositivista de Smend, si bien lo hacía precisando que la espiritualidad englobaba como momento suyo los imperativos de la naturaleza. Por otro lado, desde un punto de vista más sociopolítico, podría decirse que si Smend perseguía la politización de las masas y Kelsen intentaba la despolitización de la ciencia jurídica, Llorens pretendía mediante la ciencia despolitizar la actividad estatal otorgándole la sola misión privada de arbitrar intereses particulares.

En las construcciones de Smend el proceso integrador consistía en la actualización de una matriz axiológica unitaria, con un contenido material tangible, por parte principalmente de los órganos políticos del Estado con el fin de que los individuos la reprodujesen en sus relaciones respectivas. En la teoría de Llorens, por el contrario, el proceso integrador se refería a una ley social de carácter formal: la tendencia inmanente a la coordinación entre los intereses por razones de pura conservación, pero los contenidos específicos de dichos intereses eran variables y la actualización de esa ley social no se producía por mediación estatal, sino a través de las acciones individuales conscientes de su mutua interdependencia.

La propuesta teórica de Smend fue interpretada en su tiempo como expresión de la «crisis del Estado» provocada por la conclusión de la época

16 Véase Kelsen, 1997: 15, 20-21, 26, 48, 50-51, 74, 91, 95-96 y 142. Sobre su polémica con Smend, pueden consultarse los estudios de Carlos Miguel Herrera (1997: 175190), Agelo Abignente (1992: 224 ss.), J. A. Estévez Araujo (1988: 106-110) y Stephan Korioth (2005). 
liberal. Esta mutación histórica se reflejó en la teoría estatal de tres modos: su desconexión respecto de los principios liberales, la caída del mito de un "conocimiento libre de valores», con la consiguiente «politización de la ciencia del Estado», y la conversión de la Volksgemeinschaft en una suerte de "postulado» epistemológico capaz de desbancar a la "teoría de la lucha de clases» (Mayer, 1931: 23, 28-9). Llorens compartía la idea de que competía al derecho constitucional proporcionar instancias de mediación capaces de superar las «contraposiciones de clase», pero no creía que para ello fuese necesario renunciar a las aspiraciones liberales de una ciencia social libre de sesgos particularistas, de un derecho como expresión de la justicia y de una integración producida por el propio movimiento espontáneo de la sociedad, no por la adecuación de esta a los mandatos del Estado.

Con lo abordado hasta ahora quedan bien patentes las discrepancias entre los modelos teóricos de Llorens y de Smend: mientras que para el primero la Integrationslehre servía para mirificar el Estado, y preparaba así el terreno a la tiranía, para el segundo la idea privatista de la coordinación entre los intereses ejemplificaba el apoliticismo propio de la desfasada doctrina liberal. Si a juicio de Llorens la adhesión irracional a los valores de la comunidad no podía fundamentar la política, y su correcto estatuto era el de componer un momento subordinado a la racionalmente cognoscible solidaridad entre las necesidades, en opinión de Smend la armonía espontánea de las pulsiones sociales había sido desmentida por los hechos, había quedado al descubierto su -ideológica - función limitadora de la política y, en consecuencia, constituía ya una base notoriamente frágil para sustentar el Estado, por lo que debían buscarse unos supuestos más sólidos que, antecediendo a cualesquiera divergencias, compusiesen una unidad firme, perdurable y abarcadora de todas las contraposiciones sociales.

\section{LECTURAS CONTEMPORÁNEAS DE LA INTEGRATIONSLEHRE}

El motivo principal de la distancia que separaba a Llorens de Smend se cifra entonces en su desigual concepción del principio del orden social. Para que salga a la luz la diversa naturaleza que ambos pensadores confirieron a tal principio, en lo que atañe a la doctrina de Smend, acaso resulten insuficientes las variadas interpretaciones que ha obtenido hasta el momento.

A este respecto, poco ha aportado la historia tradicional de las ideas, según la cual, cuando nos enfrentamos a una teoría, debemos reconstruir las circunstancias de su creación, relatar los antecedentes que hasta ella han conducido y seguir su rastro en obras posteriores (Korioth, 1990; Lucas Verdú, 1987: 20 y ss., 51 y ss., 108 y ss.). La dogmática constitucional, cuando se 
muestra falta de sentido historiográfico, no suministra tampoco criterio útil para nuestra búsqueda al desdeñar el estudio de lo que no le resulta inmediatamente aprovechable para sus fines exegéticos (García Roca, 1988: 270, 273 y 275). Si bien puede proporcionar a la razón práctica alguna orientación útil, la filosofía política tampoco ha conseguido iluminar el contenido de la doctrina de la integración cuando, identificándola forzadamente con el mito soreliano de la huelga general, la desautoriza retrospectivamente por no amoldarse a los cánones de la teoría pluralista y democrática dominante en la actualidad (La Torre, 2006: 145, 153, 159, 188-190).

Mayor relieve tienen a nuestros efectos los intentos de inscribir la aportación de Smend en el Methodenstreit del constitucionalismo weimarés, aunque con frecuencia la clasificación de corrientes y la ubicación de autores resulten discutibles y, en todo caso, al ocuparse de cuestiones epistemológicas no se interroguen acerca del nervio político de su teoría ${ }^{17}$. La referencia al debate metodológico, y a la posición que en él ocupó Smend, se hace además analíticamente inutilizable cuando, en lugar de recrear la morfología de aquella controversia científica, se la aborda tomando partido por alguno de los contendientes con la finalidad de inspirar la doctrina constitucional vigente (Gallego Anabitarte, 1961: 22-23 y 30). Aunque tal propósito pueda resultar ética y políticamente irreprochable, cabe, en cambio, cuestionar la pertinencia de apoyar las preferencias científicas en razones políticas, pues derivar de determinadas direcciones metodológicas consecuencias institucionales unilaterales significa desconocer que una misma idea es susceptible de apropiaciones opuestas en el terreno de la prácticas sociales, y tan concebible es entonces una defensa meditada de la democracia parlamentaria por parte del positivismo jurídico como de las corrientes éticas objetivas ${ }^{18}$.

Ocupada ya la observación científica en desbrozar el principio de unidad propuesto por Smend, tampoco se avanza demasiado si se lo cataloga entre las manifestaciones del institucionalismo ético (Lhotta, 2005: 43-46), pues permanece indescifrada la institución que, según Smend, debía materializarse y actualizarse a través de las decisiones políticas. Aunque sea certero considerar la integración como un llamamiento a la construcción solidaria del Estado, ni

17 Rennert, 1987: 51-66. Para mayor abundamiento, véase la valiosa obra de Stolleis (1999).

18 Es muy revelador que mientras para algunos (Gallego Anabitarte, 1961: 28) «justamente fueron los llamados "positivistas" los que respetaron el Orden constitucional, y fue la "nueva doctrina" la que con su integración, decisionismo, idea del derecho, contribuyó a la catástrofe», para otros (Lucas Verdú, 1987: 210, 244255) fue la «indiferencia ante los valores» característica del positivismo la que coadyuvó a la implantación del totalitarismo. 
siquiera de este modo se logra esclarecer su contenido, pues precisamente el problema consiste en dilucidar el expediente a través del cual, a juicio de Smend, se hacía posible la reconciliación social a través del Estado. Quienes discurren de este modo, como Gustavo Zagrebelsky y Michael Stolleis, logran situar perfectamente los términos del problema, pero quizá truequen un rasgo de época por la intención subjetiva de un autor singular, dado que casi todos los constitucionalistas del momento rivalizaban en la tarea de proponer modos de superar «la crisis a través de la pacificación y la reconciliación por medio de valores comunes ${ }^{19}$ ".

El favor más flaco al conocimiento de la contribución de Smend lo hace la consueta tendencia a relacionar con el totalitarismo las obras elaboradas justo con anterioridad a su advenimiento, para poder calibrar así proximidades, apoyos, inspiraciones, resistencias y, finalmente, depurar responsabilidades ${ }^{20}$. Colocada entonces en las inmediaciones de una especie de bucle histórico, la Integrationslehre puede ser empujada a su interior, y ser comprendida como una contribución culpable al fatal y nefasto desenlace, o, por el contrario, los esfuerzos pueden dirigirse a exonerarla de toda responsabilidad y a hacer creer que, pese a sus referencias admirativas del fascismo, Smend no estaba prescribiendo remedios que se revelaron bárbaros.

La primera interpretación ${ }^{21}$ cuenta con un momento de verdad en la medida en que se apoya en pruebas incontrovertibles, como son las citadas simpatías de Smend por la ciencia política fascista, el hecho de que su doctrina fuese claramente susceptible de ser instrumentalizada por modelos autoritarios y su ulterior consideración de la época nazi como «nueva objetividad» en la que la «racionalidad», al modo hegeliano, se había realizado (1994c: 359). Sin embargo, cabe disentir de la citada lectura no solo por la escasa idoneidad historiográfica de sus reproches retrospectivos, sino ante todo por la costumbre habitual entre los que ejercemos profesiones culturales de sobrevalorar con notorio envanecimiento nuestro propio quehacer, lo cual, en el caso particular de la historia cultural del período que nos ocupa, se traduce en deducir los hechos político-sociales de las teorías sociopolíticas, descuidando así la constante mediación de la praxis en la configuración y aplicación de las ideas y, por supuesto, en la implantación de cualquier sistema institucional. Esta lectura aprecia además deficientemente los términos de la relación entre el Smend de los años veinte y el fascismo, pues, a mi entender, más que un elogio explícito

19 Zagrebelsky, 1988: 30. Stolleis (1999: 102) caracteriza la doctrina de Smend como Hoffnung auf "Integration».

20 Contra ello previene el propio Stolleis (1999: 153).

21 De la que daría ejemplo el trabajo de Carl Roehrssen (1982: 117 y ss.). 
a la labor de Mussolini, lo que se encuentra en su Verfassungsrecht es un aplauso a un tipo de literatura que, descargada de gravámenes teóricos, se ponía al servicio del Gobierno para explorar «nuevos modos de dinámica estatal» que reconquistasen el consenso (Smend, 1985a: 68-69).

La otra línea interpretativa se ampara en la deliberada ambivalencia de la propuesta de Smend. Encontraría un asidero importante en la oportunista matización que, tras la Segunda Guerra, hizo el autor de su propia teoría, identificando ahora los valores comunitarios con los valores constitucionales (Smend, 1994e: 480-481; 1994f: 484-485) y contemplando ya el III Reich como un momento de desintegración estatal a manos del Partei (1994d: 366). También se podría agarrar a la importancia que otorgaba al parlamentarismo (medio de integración funcional) y a las invocaciones expresas que en su obra de 1928 hacía "del ciudadano consciente y participativo» (1985a: 58). A mi juicio, a esta aproximación puede replicársele que cuando Smend se refería a la participación política ${ }^{22}$ no lo hacía en el sentido de la participación democrática consciente, que para él resultaba accesoria y prescindible, sino en el de la pertenencia cultural, refleja e inconsciente de los individuos a su comunidad, lo cual, sociológicamente considerado, equivalía a su adhesión a los valores gubernamentales, condición anímica indispensable para su ulterior incorporación a una sociedad unificada por el Estado ${ }^{23}$. De otra parte, puede asimismo objetársele que para el Smend de entreguerras la Constitución, lejos de materializar la voluntad constituyente y de crear originariamente los valores normativos que habían de plasmarse en la sociedad, reflejaba más bien un conjunto de valores preexistentes a los que se hallaba permanentemente sometida. Por eso no cabría identificar la integración en su declinación smendiana con el problema «de los valores establecidos por la Constitución capaces de fundar la unidad de una comunidad política ${ }^{24} \%$.

22 Sostiene este parecer Gozzi (1988: 337), para quien Smend trataba de fundar el orden político en las «complejas formas de participación en la formación de la voluntad política». En similar sentido, entendiendo que Smend tenía como horizonte "la ética pública del ciudadano consciente y activo», Zagrebelsky (1988: 14), quien, no obstante, apunta finalmente la potencial deriva autoritaria de la teoría de Smend (p. 31). También Estévez Araujo (1988: 225) recuerda la dimensión inclusiva del concepto «integración», descuidando acaso el presumible carácter impuesto de dicha inclusión.

23 Contra esta interpretación, con indicaciones acertadas a mi entender, véase M. la Torre (2006: 144-145). Como apoyo documental de la línea aquí sostenida, basta recordar la opinión de Smend sobre la dictadura y la guerra, «máximo grado de compromiso e integración en el Estado» según sus palabras (Smend, 1985a: 99 y 174).

24 Como hace G. Gozzi (1988: 304, 315-323). Aun así, en ese mismo texto, el autor reconoce que Smend está más bien aludiendo a la constitución material (p. 323), y, en 


\section{AUTOCONSERVACIÓN CONTRA NACIÓN}

Si los acercamientos mencionados no llegan a precisar del todo el contenido político de la Integrationslehre es, en mi opinión, por un motivo fundamental: suele realizarse una lectura excesivamente atenida a la economía expositiva y a la terminología del propio Smend, que lleva a identificar sin más los elementos que componen la integración material con los «valores materiales y espirituales» que instituyen una colectividad política. Pero en un tiempo en que los valores se hallaban completamente socializados, como comenzaba a ser el de entreguerras y como lo es ya plenamente el nuestro ${ }^{25}$, no basta con reflejar la constante invocación que Smend hacía de esos valores ${ }^{26}$, sino que se trata de desentrañar su contenido específico.

En lo que a esto concierne, son dignas de atender las advertencias que indican una presencia de la teología evangélica en la teoría de la integración ${ }^{27}$, las lecturas que hacen de «la autoconservación del Estado» su objetivo secreto (Abignente, 1992: 220) y los análisis que, inquiriéndose acerca del a priori omnipresente en la doctrina de Smend, concluyen por colocarlo entre los «nostálgicos» que aspiraban a restaurar «el afortunado equilibrio de las constituciones decimonónicas» (Bisogni, 2005: 61-64 y 80-84). En esta última línea, destaca por su acierto la visión de la Integrationslehre como una suerte de «regreso» a la categoría romántica del Volksgeist (Stolleis, 1999: 102). No obstante, creo que la clave para desvelar el sentido de los citados «valores sustantivos» consiste en referirlos a la propia diagnosis formulada por Smend, que, en consonancia con otros autores (Heller, 1985: 246, 254), pero extrayendo de ella conclusiones diferentes, apuntaba siempre a la extendida Entpolitisierung como causa de los males sociales y, por tanto, como objetivo principal a abatir con el fin de recuperar el espacio perdido de lo público. Enfocado el análisis desde dicha perspectiva, se trataría entonces de averiguar qué estrategias de politización masiva proponía Smend, y en este sentido pienso que su obra planteaba abiertamente el fomento de la identidad nacional por parte los

otro texto posterior, termina rectificando su interpretación democrática de Smend para ubicarlo más correctamente en la tradición organicista (2003: 101, n. 72).

25 Seńalaba esta evidencia, expresada no obstante como una crítica retrospectiva a Smend, y no como una prevención metodológica, Werner S. Landecker (1950/51: 45).

26 Así lo continúa haciendo, sin agregar complejidad al término «valor», S. Korioth (1999: 208-213).

27 Las realiza Jörg Luther (1987: 200-203) y las reconocía el mismo Smend (1994f: 486). Discrepo, en cambio, de la relación que establece este autor entre el léxico de Smend y «la sociología organicista de Spencer», p. 204, autor cuyas construcciones eran calificadas por Smend de «estrictamente mecanicistas» (1985: 63 n. 55). 
gobernantes con el fin de sustituir el divisivo mito de la clase por el mito unitivo de la nación.

Abundan los indicios que señalan a la nacionalización de las masas como el propósito implícito de la Integrationslehre y a la nación alemana como el contenido tácito de los valores comunitarios ${ }^{28}$. Para comenzar, Smend identifica no por azar su idea de integración con el plebiscite de tous les jours con que Ernest Renan contestaba a la pregunta Qu'est-ce qu'une nation? Por otra parte, la retórica nacionalista no le era en absoluto ajena cuando, al referirse a la «unidad política» en que el Estado consiste, la entendía como una "realidad histórica» y la ejemplificaba en las batallas célebres que permitían tomar "conciencia» de ella, o en «la lucha contra fracasos y dificultades» comunes que avivaba el sentimiento de co-pertenencia a una comunidad. Resulta además esclarecedor que los «símbolos políticos» escogidos por Smend para encarnar la sustancia espiritual de las colectividades manifestasen todos directamente la identidad nacional, como lo hacían «las banderas, los escudos, los Jefes de Estado y las fiestas nacionales». Puede incluso añadirse el dato de que, seleccionando obras teóricas afines a la suya, Smend mencionase, sin citar el título, un estudio de Hauriou (1912: 129-154) sobre la soberanía nacional, en el cual se fundamentaba - y limitaba- el poder estatal por «la voluntad general de la nación», esto es, por un principio superior y de mayor fijeza que la mera e individualista «voluntad electoral», dada su naturaleza orgánica y el que emanase de la constitución histórica de la colectividad. Por último, en un opúsculo posterior a su Verfassungsrecht, el mismo Smend (1985b: 266) confesaría que el «contenido esencial de la Constitución» y el cumplimiento por parte del ciudadano de su status "dentro del todo» tenían como fin alcanzar la «misión histórica y moral [que] en cuanto nación» Alemania tenía encomendada.

Una vez enfocado el texto de Smend desde el ángulo propuesto, las evidencias no cesan de aumentar (Smend, 1985a: 94 n. 130, 96 n. 135, 97, 113, 117 y 127). Basten varios ejemplos ańadidos: Smend planteaba su crítica al Tratado de Versalles, no alegando «la escasez de los medios» para afrontar las retorsiones en él previstas, sino aludiendo a sus efectos perniciosos en «la identidad propia de un gran Estado nacional». Situaba «el problema específico de la integración» en la fragilidad de "la participación», es decir, del patriotismo, en comunidades políticas de gran extensión territorial. Creía que «la vinculación personal» con el propio Estado se agudizaba cuando se contraponía a la existencia de "otros Estados», asociando el fin de la política exterior con el «prestigio» nacional en el extranjero. Entre las medidas adoptadas por el

28 Para las pruebas entresacadas a continuación, véase Smend (1985: 63, 94, 97 n. 137, 101, 121-124). 
fascismo, encomiaba el uso de la mitología nacional como estrategia integradora $^{29}$. Y remataba su exposición metodológica añorando la simplicidad de las filosofías políticas extranjeras, sencillez y unilateralidad que atribuía "a un hecho tan poco problemático como e[ra] la existencia de una unidad nacional en Francia, en Inglaterra o en los Estados Unidos».

En definitiva, creo que al entender el Estado como la realización de los valores constitutivos de una comunidad, Smend lo concebía, sin excesiva novedad, como la expresión jurídica del ser unitario de la nación. Podría objetarse que la doctrina de la integración no tenía el sentido tradicionalista inherente al término nación, pero, aparte de las alusiones explícitas de Smend a la historia, cabría responder que en aquellos tiempos, desmedrado tras la Gran Guerra el prestigio de la tradición como factor aglutinante, era habitual que los nacionalistas invirtiesen su retórica y, en lugar de acudir al valor ejemplar del pasado, hablasen de ilusionantes empresas de futuro e identificasen la nación con la «realización del ideal» colectivo o con la entrega a un «destino histórico común» (Duguit, 1924: 89; Pérez Serrano, 1984: 113; el propio Smend, 1994c: 358).

Identificado de este modo el contenido político de la Integrationslehre, puede ahora concluirse que a los atributos de la nación Llorens oponía los imperativos de la autoconservación. Su crítica a la doctrina de Smend no se alineaba entonces ni con el formalismo que consideraba la integración un fenómeno psicosociológico ni con la filosofía crítica que denunciaba las tentativas «de establecer un vínculo irracional entre las masas» para legitimar «una política que no era la de ellas» (Horkheimer, 1998: 167).

La postura de Llorens reproducía en primer lugar las convicciones con que el racionalismo decimonónico enfrentaba el auge de la política de masas. Un valioso testimonio de esta actitud se encuentra en la tesis inédita de Eugenio M. ${ }^{a}$ Vilaclara sobre el valor en derecho político de la sugestión. Para este joven jurista, estaba "fuera de duda» que «si el hombre pudiese sustraerse al influjo político» irracional promovido por la prensa, los partidos políticos y los aparatos estatales, entonces, liberado ya de las perturbadoras mediaciones del irracionalismo, su «actividad se dirigiría á estos dos imperativos de la ley económica: consérvate y trabaja» (Vilaclara, 1908: 137-138, 157, 243 y ss., 285), de los que podría inferirse con eficacia el orden en sociedad.

La contestación de Llorens a la Integrationslehre se desenvolvía además en el interior de los esquemas que, en el momento de la socialización democrática,

29 Puede aquí añadirse que es precisamente su silenciosa invocación de la unidad nacional lo que acerca a Smend al fascismo descrito, por ejemplo, por Corrado Petrone (1929: 101 y ss.). 
desplegaban con energía los autores más conservadores. Un fiel ejemplo de tal corriente lo encarna José Gómez de la Serna (1950: 32-35), quien combinaba una cerril defensa de la dictadura con la consabida contraposición entre, de un lado, la «constitución natural de la sociedad» y los «fines espontáneamente impuestos» por ella y, de otro, «el Derecho positivo» y «la autoridad estatal», a los que solo cumplía «reproducir y sistematizar», nunca «desviar y forzar», dicha «constitución política real de la sociedad». Llorens trascendía de todos modos este razonamiento hasta cierto punto maniqueo, y lo hacía a través del lenguaje dialéctico, reproduciendo consignas teóricas muy próximas a las esgrimidas por Dietrich Schindler, en cuya concepción del soziale Ganzes las relaciones individuales no se unificaban en virtud de una sustancia orgánica antecedente, sino por obra de un entramado irrompible de funciones y medios que interconectaba a todos los sujetos sociales formando una totalidad objetiva, multipolar y autorregulada $^{30}$.

La distancia que media entre el principio del orden que Llorens y Smend postularon se deja ver cuando abordaban asuntos colaterales como el estatuto político del territorio, soporte geográfico de «vivencias espirituales» para Smend (1985a: 104-105), y espacio de «las posibilidades económicas fundamentales de subsistencia" para Llorens (1932: 24). También se torna visible si vamos más allá de su común adscripción a una misma corriente filosófica y constatamos la ausencia en Llorens de divisiones conceptuales primordiales en la reflexión de Smend, como la contraposición entre naturaleza y cultura ${ }^{31}$, que el constitucionalista catalán disolvía al referir lo cultural al acontecimiento natural de la satisfacción de las necesidades. Además, divergiendo sus diagnósticos sobre las causas de la crisis, resulta coherente que propusiesen remedios desiguales, pues, más que letargo político y desafección institucional, Llorens encontraba en las masas un exceso de politización que, alimentando deseos irrealizables, interfería en la percepción racional de las reglas inmanentes de la convivencia.

De ahí que, en lugar de la Integrationslehre, y su continua alusión a categorías sentimentales, Llorens prefiriese tomar de Smend su análisis del derecho constitucional no escrito ${ }^{32}$, pues en él se remitía a un principio

30 Schindler, 1932: 59, y, más en general, «III.2. Das soziale Leben als ein Ganzes». Por eso no puede convenirse con Lucas Verdú (1987: 125-130) en su calificación de Schindler como el trasunto suizo de Smend.

31 «El Estado no es un fenómeno natural [...] sino una realización cultural» (Smend, 1985a: 61).

32 Llorens, 1933a: 196. Llorens se refería a un temprano trabajo de Smend donde analizaba relaciones entre la Federación y los Estados miembros regidas por reglas técnicas y consuetudinarias, o de cortesía y lealtad, no previstas en la Constitución (Smend, 1994a: 39 y ss.). 
basilar de su propio pensamiento, según el cual la normatividad jurídica explícita no agotaba, ni determinaba inexorablemente, la facticidad social, sino que, por el contrario, las normas políticas, incluidas las constitucionales, corroboraban, complementaban y siempre habían de presuponer la estructura coordinante de la colectividad. Y es que era a esta a la que continuamente aludía la idea de integración sostenida por Llorens (1933a: 138, 175), formulada también contra el normativismo, pero con el propósito de resaltar «la interdependencia en la satisfacción de intereses» y el vínculo inquebrantable que, cimentando el Estado, conectaba a todos los asociados con «la integración total».

Resulta en este sentido esclarecedor que utilizase la «expresión» «integración política» en "su significado etimológico», separándose de la acepción «convencional» que usaban "otras obras contemporáneas» (1933b: 104), como la de Rudolf Smend. La que él empleaba remitía, pues, a la noción de «entero» (Corominas, 1983: 236 y 338), y, más concretamente, a la «acción y efecto de hacer algo entero usando partes ${ }^{33_{\eta}}$. El concepto que manejaba respondía a la suma del prefijo de negación in- y del verbo tangere, designando entonces lo "no tocado", lo incorrupto, en un acto de evocación de la idea de "pureza originaria». No es gratuita esta deliberada fundamentación etimológica. El Estado era para Llorens el momento de síntesis de la multiplicidad y la pluralidad inherentes a lo social, no la reproducción de una identidad colectiva monolítica precedente. Era a este horizonte ético, y no al de la reproducción masiva de valores comunitarios o nacionales, al que se dirigía la doctrina de la integración de Llorens. Mas no se piense que oponía a la integración romántica de Smend la solidaridad espontánea entre los individuos porque confiase en su bondad y sociabilidad innatas. Sucedía lo contrario: participando del pesimismo antropológico, y teniendo entonces muy en cuenta el carácter egoísta e insociable del hombre, lo que este jurista sostenía es que el imperativo inclemente de la supervivencia pacificaría tarde o temprano las relaciones sociales. Por este profundo realismo, y pese a su elementalidad, algunos constitucionalistas del momento pensaron que la idea de integración de Llorens merecía mayores plácemes que la de Smend ${ }^{34}$.

33 Para las siguientes consideraciones, véase el Diccionario etimológico español en línea, voz «integración».

34 No está de más recordar que Carlos Sanz Cid pensaba que la teoría de Llorens «supera a la de Smend al orientarse hacia la coordinación» entre los intereses y no - se entiende- hacia la subordinación. El juicio se encuentra en el expediente de oposiciones que ganó Llorens, depositado en la caja del Archivo General de la Administración, sig. 32/13466. 


\section{Bibliografía}

Abignente, A. (1992). Il contributo di Rudolf Smend ed Hermann Heller al dibattito weimariano su diritto e stato. Quaderni Fiorentini, 21, 213-257.

Adorno, T. (2005). Dialéctica negativa. Madrid: Akal.

Anter, A. (2009). Rudolf Smend und Kampf gegen den Ordnung relativismus. En A. Brockmöller y E. Hilgendorf (Hg.). Rechtsphilosophie im 20. Jahrhundert (pp. 37-50). Stuttgart: Franz Steiner.

Bisogni, G. (2005). Weimar e l’unità politica e giuridica dello Stato. Napoli: Edizione Scientifiche Italiane.

Conde, F. J. (1942). Introducción al Derecho político actual. Madrid: Escorial.

Corominas, J. (1983). Breve diccionario etimológico de la lengua castellana. Madrid: Gredos.

Costa, P. (2001). Civitas. Storia della cittadinanza in Europa. IV. L'età dei totalitarismi e della democrazia. Roma; Bari: Laterza.

Duguit, L. (1924). Soberania y libertad. Lecciones dadas en la Universidad de Columbia. Madrid: Beltrán.

Estévez Araujo, J. A. (1988). La crisis del Estado de Derecho liberal. Schmitt en Weimar. Barcelona: Ariel.

Foucault, M. (1997). Las palabras y las cosas. Madrid: Siglo XXI.

Gallego Anabitarte, A. (1961). La discusión sobre el método en Derecho público durante la República de Weimar (ciencias del espíritu y método jurídico). Revista Española de Derecho Constitucional, 46, 11-37.

García Amado, J. A. (1997). Estudio preliminar. En H. Kelsen. El Estado como integración. Madrid: Tecnos.

García Fernández, J. (2016). Estudio preliminar. En J. García Fernández (ed.). Antología de la Revista de Derecho Público (1932-1936). Madrid: Centro de Estudios Políticos y Constitucionales.

García Roca, F. J. (1988). Sobre la teoría constitucional de Rudolf Smend. Revista de Estudios Políticos, 59, 269-276.

García Santos, J. F. (1980). Léxico y política de la Segunda República. Salamanca: Universidad de Salamanca.

Gómez de la Serna y Favre, J. (1950) [1933]. Filósofos modernos del Derecho: Rudolf Smend. Revista de Estudios Politicos, 54, 17-55.

Gozzi, G. (1988). Modelli politici e questione sociale in Italia e in Germania fra Otto e Novecento. Bologna: Il Mulino.

- (2003). Democrazia e diritti. Germania: dallo Stato di diritto alla democrazia costituzionale. Roma: Laterza.

Guillén Kalle, G. y Almoguera Carreres, J. (2006). Eduardo L. Llorens y Clariana y el Derecho Constitucional en la Segunda República Española. Madrid: Reus.

Gurvitch, G. (1932). Lidée du droit social. Paris: Recueil Sirey.

Hauriou, M. (1912). La souveraineté nationale. Recueil de Législation de Toulouse, 8, 1-154.

Heller, H. (1985) [1932]. Ciudadano y burgués. En Escritos políticos (pp. 241-256). Madrid: Alianza. 
Herrera, C. M. (1997). Théorie juridique et politique chez Hans Kelsen. Paris: Kimé.

Horkheimer, H. (1998) [1936]. Egoísmo y movimiento liberador. En Teoría crítica (pp. 151222). Buenos Aires: Amorrortu.

Jakab, A. (2010). Dos paradigmas encontrados del pensamiento constitucional en Europa: Austria y Alemania. Revista Española de Derecho Constitucional, 88, 131-162.

Kelsen, H. (1997) [1930]. El Estado como integración. Una controversia de principio. Madrid: Tecnos.

Koellreutter, O. (1929). Integrationslehre und Reichsreform. Tübingen: Mohr.

Korioth, S. (1990). Integration und Bundesstaat. Ein Beitrag zur Staats - und Verfassungslehre Rudolf Smends. Berlin: Ducker und Humblot. Disponible en: https://doi. org/10.3790/978-3-428-06991-0.

— (1999). Integration von Norm, Wert und Wirklichkeit. En Maria-Sibylla Lotter (Hrsg.). Normenbegründung und Normenentwicklung in Gesellschaft und Recht. Baden-Baden: Nomos.

- (2005). „... sowiet man nicht aus Wien ist oder aus Berlin“. Die Smend/Kelsen-Kontroverse. En Stanley L. Paulson y Michael Stolleis (Hrsg.). Hans Kelsen. Staatsrechtslehrer und Rechtstheoriker des 20. Jahrhunderts. Tübingen: Mohr.

Kuhn, Th. S. (1987). Qué son las revoluciones científicas. En ¿Qué son las revoluciones científicas? y otros ensayos (pp. 59-93). Barcelona: Paidós.

Landecker, W. S. (1950/51). Smend's theory of integration. Social Forces, 29, 39-48. Disponible en: https://doi.org/10.2307/2572755.

La Torre, M. (2006). La crisi del Novecento. Giuristi e filosofi nel crepuscolo di Weimar. Bari: Dedalo.

Lepsius, O. (2008). El redescubrimiento de Weimar por parte de la doctrina del Derecho político de la República Federal. Historia Constitucional, 9, 259-295.

Lhotta, R. (2005). Rudolf Smends Integrationslehre. En Die Integration des modernen Staates. Zur Aktualität der Integrationslehre von Rudolf Smend. Baden-Baden: Nomos. Disponible en: https://doi.org/10.5771/9783845295275.

Llanque, M. (2006). Die politische Theorie der Integration: Rudolf Smend. En A. Brodocz y G. S. Schaal (Hrsg.). Politische Theorien der Gegenwart, vol. 1. Opladen: B. Budrich.

Llorens, E. (1932). La autonomía en la integración politica. Madrid: Revista de Derecho Privado.

- (1933a). Notas sobre el concepto, método, fuentes y programas de Derecho político. En S. Martín et al. El derecho político de la Segunda República (pp. 133-247). Madrid: Dykinson, Universidad Carlos III.

- (1933b). Reseńa de La autonomía en la integración politica. Revista Alemana, 2 (5-6), 104.

- (1934a). La igualdad ante la ley. Murcia: Instituto de Estudios Políticos de la Universidad de Murcia.

— (1934b). El Estado y sus órganos. Discurso leido en la solemne apertura del curso académico de 1934 a 1935. Madrid: Imprenta Sucesores de Nogués.

Lucas Verdú, P. (1976). Curso de Derecho politico, t. I.: Introducción: concepto, método, escuelas. Madrid: Tecnos. 
- (1987). La lucha contra el positivismo jurídico en la República de Weimar. La teoría constitucional de Rudolf Smend. Madrid: Tecnos.

Luther, J. (1987). Rudolf Smend: genesi e sviluppo della dottrina dell'integrazione. En G. Gozzi y P. Schiera (a cura di). Crisi istituzionale e teoria dello Stato in Germania dopo la Prima guerra mondiale. Bologna: Il Mulino.

Martín, S. (2011). El derecho politico de la Segunda República. Madrid: Dykinson.

Mayer, H. (1931). Die Krisis der deutschen Staatslehre und die Stattsauffassung Rudolf Smends. Köln: Friedrich Lill.

Medina Echavarría, J. (1935). La situación presente de la Filosofía jurídica. Esquema de una interpretación. Madrid: Revista de Derecho Privado.

Molina Cano, J. (2005). Eduardo L. Llorens y Clariana. En M. Peláez (ed.). Diccionario crítico de juristas españoles, portugueses y latinoamericanos (vol. I). Málaga: Cátedra de Historia del Derecho y de las Instituciones.

Morlok, M. y Schindler, A. (2005). Smend als Klassiker. En Roland Lhotta (Hrsg.). Die Integration des modernen Staates. Zur Aktualität der Integrationslehre von RudolfSmend (pp. 13-35). Baden-Baden: Nomos. Disponible en: https://doi.org/10.5771/9783845295275-12.

Oppenheimer, F. (1990) [1929]. Der Staat. Eine soziologische Studie. Berlin: Libertad.

Pérez Serrano, N. (1932). El proyecto de Constitución portuguesa. Revista de Derecho Público, 1, 211-233.

- (1984). Tratado de Derecho político. Madrid: Civitas.

Petrone, C. (1929). Stato e Nazione nella concezione fascista. En F. Turati y G. Bottai. La Carta del Lavoro (pp. 101-108). Roma: Diritto del Laboro.

Rennert, K. (1987). Die 'geisteswissenschaftliche Richtung' in der Staatsrechtslehre der Weimarer Republick. Berlin: Duncker und Humblot.

Roehrssen, C. (1982). La Integrationslehre di Rudolf Smend: un sintoma significativo della patogenesi del nazismo. Materiali per una storia della cultura guridica, 12, 117-129.

Schindler, D. (1931). Recht und Staat. Verhandlungen des Schweizerischen Juristenvereins, 2, 219-273.

- (1932). Verfassungsrecht und soziale Struktur. Zürich: Schulthess.

Smend, R. (1985a) [1928]. Constitución y Derecho constitucional. Madrid: Centro de Estudios Constitucionales.

- (1985b) [1933]. Ciudadano y burgués en el Derecho público alemán. En R. Smend. Constitución y Derecho constitucional (pp. 249-268). Madrid: Centro de Estudios Constitucionales.

(1994a) [1916]. Ungeschriebenes Verfassungsrecht im monarchischen Bundesstaat. En R. Smend. Staatsrechtliche Abhandlungen und andere Aufsätze (pp. 39-59). Berlin: Duncker und Humblot. Disponible en: https://doi.org/10.3790/978-3-428-08080-9.

— (1994b) [1923]. Die politische Gewalt im Verfassungsstaat und das Problem der Staatsform. En R. Smend. Staatsrechtliche Abhandlungen und andere Aufsätze (pp. 68-87). Berlin: Duncker und Humblot. Disponible en: https://doi.org/10.3790/978-3-428-08080-9. (1994c) [1943]. Politisches Erlebnis und Staatsdenken seit dem 18. Jahrhundert. En R. Smend. Staatsrechtliche Abhandlungen und andere Aufsätze (pp. 346-362). Berlin: Duncker und Humblot. Disponible en: https://doi.org/10.3790/978-3-428-08080-9. 
- (1994d) [1945]. Staat und Politik. En R. Smend. Staatsrechtliche Abhandlungen und andere Aufsätze (pp. 363-379). Berlin: Duncker und Humblot. Disponible en: https:// doi.org/10.3790/978-3-428-08080-9.

- (1994e) [1956]. Integrationslehre. En R. Smend. Staatsrechtliche Abhandlungen und andere Aufsätze (pp. 475-481). Berlin: Duncker und Humblot. Disponible en: https:// doi.org/10.3790/978-3-428-08080-9.

- (1994f) [1966]. Integration. En R. Smend. Staatsrechtliche Abhandlungen und andere Aufsätze (pp. 482-485). Berlin: Duncker und Humblot. Disponible en: https://doi. org/10.3790/978-3-428-08080-9.

Stolleis, M. (1999). Geschichte des Öffentlichen Rechts in Deutschland. Vol. III: 1914-1945. München: C. H. Beck.

Tomás y Valiente, F. (1997) [1989]. El «Estado integral»: nacimiento y virtualidad de una fórmula poco estudiada. En Obras completas, III. Madrid: Centro de Estudios Políticos y Constitucionales.

Tönnies, F. (1947). Comunidad y sociedad. Buenos Aires: Losada.

Turati, A. y Bottai, G. (1929). La Carta del Lavoro. Illustrata e commentata. Roma: Il diritto del lavoro.

Unruh, P. (2004). Weimarer Staatsrechtslehre und Grundgesetz. Ein verfassungstheoretischer Vergleich. Berlin: Duncker und Humblot.

Vilaclara, E. M. (1908). La sugestión: su valor en el Derecho politico [tesis doctoral inédita]. Universidad Complutense.

Weber, M. (1991) [1918]. Parlamento y Gobierno en una Alemania reorganizada. Una crítica política de la burocracia y de los partidos. En Escritos políticos. Madrid: Alianza.

Zagrebelsky, G. (1988). Introduzione. En R. Smend. Costituzione e diritto costituzionale. Milano: Giuffrè. 